\title{
EXCHANGE NOTES
}

Please send in immediately to Headquarters, 4580 Scott Ave., St. Louis, Mo., any changes in address, name or personnel of your library. The key list will be revised at an early date.

The key list is the property of your library. Please see that it is kept in a prominent place so that it will be available at all times.

Short lists of fragmentary "wants" will be listed in the Exchange lists as usual, but there is no demand upon the members to look these up. The members whose wants have been filled have been very appreciative in the past, but the main purpose of the Exchange still continues as a clearing house for duplicates which must be moved.

If any members feel they must sell complete duplicate sets, long runs or single volumes, these may be advertised in the Bulletin (write Mr. Harding for cost of advertising).

Greater care should be taken this year in listing your material accurately and in distributing and addressing packages. The manager will do her share in being extra careful. Money for postage or express is too scarce, and should not be used needlessly.

Note the increase in 1st class postage and the increase in parcel post rates effective October 1 st. The preferred method of transportation remains express collect.

Yours for a busy year,

ELLA B. LAWRENCE

Manager of the Exchange.

\section{J. A. M. A. 99: 1001, Sept. 17, 1932 \\ QUARTERLY CUMULATIVE INDEX MEDICUS}

Volume 11, 1932, of the Quarterly Cumulative Index Medicus has just appeared. It represents the first issue since this publication was taken over completely by the American Medical Association. The book is published at considerable loss and represents a contribution by the American Medical Association to the advancement of medical science. In a desire to make the publication satisfactory to its principal users, a letter was sent early in July to all libraries subscribing to the Index, asking the opinion of librarians as to the desirability of publishing a special edition of the Index on 100 per cent rag paper so as to give it permanence. Three hundred and eighty-four letters were sent to domestic, foreign and Canadian librarians, and approximately 50 per cent of the librarians addressed have replied up to this time. Approximately 6 per cent of the librarians indicate a desire for a special edition and a willingness to pay for such a special edition at an advanced rate.

With the issuing of the present volume, arrangements have been made to improve the binding greatly without, however, increasing the cost of the Index. The binding now used has greater strength and durability than the one formerly used. 
Because of the relatively small number of librarians indicating willingness to subscribe to the rag paper edition, it has been decided not to issue the Index in this form.

The majority of letters received from librarians contain high praise for the Index as produced and commendation for the Association in publication of this work. One librarian writes, "Just as the sterilizer is the center of the hospital so is the Quarterly Cumulative Index Medicus the center around which the medical library revolves."

The letters from the librarians also indicate that most medical libraries are at this time undergoing great financial strain and relatively little expansion.

\section{CORRECTION}

Due to an unfortunate error in the Report of the Membership Committee Dr. C. W. Burr of Philadelphia was listed among the deceased members. Dr. Burr writes that he is still very much alive and engaged in active practice in Philadelphia. We offer our sincere apologies to Dr. Burr for the mistake. 